\title{
Identification of Intestinal-Type Barrett's Metaplasia by Using the Intestine-Specific Protein Villin and Esophageal Brush Cytology
}

\author{
Allison J. MacLennan, Mark B. Orringer, and David G. Beer* \\ Department of Surgery, Section of Thoracic Surgery, University of Michigan Medical School, Ann Arbor, Michigan
}

Villin is an actin-binding cytoskeletal protein required for brush-border formation in the normal small intestinal and renal proximal tubule epithelium. Villin is a marker of cell differentiation in small intestinal and renal cell lineages, and recent studies have shown villin to be highly expressed in $100 \%$ of intestinal-type Barrett's metaplasias. This epithelium is the single greatest risk factor for developing esophageal adenocarcinoma and arises when the normal esophageal squamous epithelium is replaced by a small intestine-like columnar epithelium after damage by chronic gastroesophageal reflux. In intestinal-type Barrett's metaplasia, the villin protein exhibits a highly characteristic staining pattern in which strong apical, brush-border staining of columnar epithelial cells is observed. In this study, the ability to identify intestinal metaplastic cells by using this distinct villin staining pattern was examined in endoscopic esophageal brushings from patients with confirmed Barrett's metaplasia. Esophageal brushings from 81\% (17 of 21) of patients with Barrett's metaplasia demonstrated individual columnar cells with the characteristic villin staining pattern, whereas all normal esophageal squamous cells, blood cells, and gastric columnar cells were negative for villin expression. Northern blot analysis demonstrated villin mRNA expression in Barrett's metaplasia but not in the normal squamous esophagus or gastric mucosa from the same patients. The combined use of villin immunohistochemical analysis and esophageal brush cytology may provide a simple and effective method of detecting intestinal-type Barrett's metaplasia in patients at higher risk for developing this epithelium, such as those experiencing chronic gastroesophageal reflux symptoms. Mol. Carcinog. 24:137-143, 1999. @ 1999 Wiley-Liss, Inc.

Key words: intestine; Barrett's metaplasia; villin; esophageal brush cytology

\section{INTRODUCTION}

Over the past two decades, the incidence of esophageal adenocarcinoma in the United States has increased at a rate surpassing that of any other cancer [1]. The main risk factor involved in the development of esophageal adenocarcinoma is the presence of intestinal-type Barrett's metaplasia [2]. Patients with Barrett's metaplasia are 30 to 40 times more likely to develop adenocarcinoma than the general population, although the key factors underlying the progression of Barrett's metaplasia to adenocarcinoma remain less well characterized [3]. Intestinaltype Barrett's metaplasia results when the normal stratified squamous epithelium of the esophagus is destroyed during chronic gastroesophageal reflux and is replaced by a columnar epithelium containing characteristic goblet cells [2]. Other types of esophageal injury, such as atrophic gastritis, caustic injury, bile reflux, and perhaps chemotherapy, may precede this metaplastic process $[4,5]$. In addition, approximately $12 \%$ of patients suffering from chronic gastroesophageal reflux disease develop Barrett's metaplasia [6].

To facilitate early detection of malignancies, patients with Barrett's metaplasia are often enrolled in endoscopic surveillance programs. Early detection of esophageal adenocarcinoma is essential because esophageal cancers are often diagnosed at advanced stages when metastasis has already occurred, and the prognosis at that point is usually grim [7]. Currently, there are no available methods that allow for the reliable identification of patients with gastroesophageal reflux disease who have developed premalignant intestinal-type Barrett's metaplasia, aside from endoscopy and biopsy. These procedures do involve a slight risk of complication, such as esophageal perforation, and their costs may exclude some patients with Barrett's metaplasia from surveillance programs, leaving these patients undiagnosed. The use of markers specific for the intestinal-type Barrett's epithelium would be of great value, especially if combined with the more accessible procedure of esophageal brush cytology.

\footnotetext{
*Correspondence to: B560 MSRB II, Box 0686, Department of Surgery, Section of Thoracic Surgery, University of Michigan Medical School, Ann Arbor, Ml 48109.

Received 12 June 1998; Revised 25 August 1998; Accepted 27 August 1998

Abbreviations: PBS, phosphate-buffered saline; BSA, bovine serum albumin; SDS, sodium dodecyl sulfate.
} 
We have demonstrated the high-level expression of several intestine-specific gene products in Barrett's metaplasia and esophageal adenocarcinomas that are absent in normal esophageal tissue. The enzyme sucrase isomaltase was found to be expressed at high levels in over $80 \%$ of patients with Barrett's metaplasia [8]. Aminopeptidase N, an intestinal brushborder hydrolase, is also highly expressed in Barrett's metaplasia [9], and recently we confirmed the specific and high-level expression of the cytoskeletal protein villin in 100\% of the intestinal-type Barrett's metaplasia cases examined [10]. Moreover, villin's localization pattern in Barrett's metaplasia (confined to the brush border and thus the apical surface) is quite similar to the pattern found in normal intestinal epithelium, yet villin is not expressed in normal esophageal squamous epithelium [11]. These results suggest that villin is a marker specific for intestinaltype Barrett's metaplasia and may prove useful in identifying patients with chronic reflux symptoms who may have this premalignant epithelium.

Villin is a $\mathrm{Ca}^{2+}$-regulated actin-binding protein located in the epithelial cell brush-border of the normal intestine and proximal tubules of the kidney, where it is required for apical microvilli formation [12]. The villin protein is the first brush-border enzyme to be concentrated near the apical membrane during embryonic development and plays a vital role in villus structure formation [13]. In humans, villin expression is highly regulated during embryogenesis and adulthood, and it has been suggested that villin may be used as a marker of differentiation in renal and digestive cell development [14]. In addition, the villin protein has been detected in renal cell carcinomas [15]; in gastric, colonic, and pancreatic cancers [16]; and in the serum of patients with colorectal carcinoma [17].

Identification of patients with intestinal-type Barrett's metaplasia is vital because of their higher risk for developing esophageal malignancies. Autopsy studies have indicated that the incidence of Barrett's metaplasia may be even higher than previously recognized [18]. Villin is a highly specific protein marker that may prove helpful in identifying patients with intestinal-type Barrett's metaplasia who might otherwise remain undiagnosed. In this study, we examined the immunohistochemical detection of individual columnar cells that express villin in endoscopic esophageal brushings. These brushings were obtained either at the time of surveillance or during preoperative endoscopy from patients with confirmed Barrett's metaplasia. Cytopathological analysis and villin immunohistochemical results were then compared to determine whether this method could identify Barrett's metaplastic cells in these patients. Northern blot analysis of mRNA from normal esophagus, Barrett's metaplasia, and normal gastric tissues obtained from the same patients demonstrated the specific expression of the villin gene in Barrett's metaplasia, and western blot analysis confirmed the specificity of the antibody used for identification of the villin protein.

\section{MATERIALS AND METHODS}

\section{Brushings and Specimens}

Informed consent was obtained from 31 patients ( 24 male and seven female; mean age of $56.4 \mathrm{yr}$ ) who underwent treatment at the University of Michigan Medical Center. Esophageal brushings were obtained from patients either while they were enrolled in a surveillance endoscopy program or during endoscopy before esophagectomy for cancer. Brushings of two areas of grossly appearing Barrett's metaplasia were applied to poly-L-lysine-coated microscope slides and then stored at $-20^{\circ} \mathrm{C}$. To obtain additional esophagus and gastric tissue brushings for controls, freshly resected normal esophagus and gastric tissues from patients undergoing esophagectomy for cancer were transported to the laboratory in Dulbecco's modified Eagle's medium on ice. The tissues were lightly brushed with a small plastic-bristle brush, and the cells were placed on poly-L-lysine-coated slides and stored at $-20^{\circ} \mathrm{C}$ until used.

Samples of normal esophagus, Barrett's metaplasia, and normal gastric tissue were obtained after informed consent from five patients undergoing esophagectomy for cancer at the Medical Center. These specimens were transported to the laboratory as described above, and a portion of each specimen was frozen in liquid nitrogen. The specimens were stored at $-70^{\circ} \mathrm{C}$ until used for cryostat sectioning, immunocytochemical analysis, and protein and RNA isolation.

\section{Immunohistochemical Analysis}

The localization and staining pattern of villin was determined by immunohistochemical analysis with an anti-villin monoclonal antibody (Chemicon Intl., Inc., Temecula, CA). Five-micrometer cryostat sections of tissues and esophageal brushings were briefly air dried and then fixed in $100 \%$ acetone at $-20^{\circ} \mathrm{C}$ for $10 \mathrm{~min}$. All of the following incubations were performed inside a humidified incubation chamber. Endogenous peroxidase activity was quenched by four incubations with a $0.5 \% \mathrm{H}_{2} \mathrm{O}_{2}$ solution in phosphate-buffered saline (PBS) for $20 \mathrm{~min}$ each. The slides were rinsed in PBS three times for $5 \mathrm{~min}$ each time and then incubated with a 1:20 dilution of normal horse serum in PBS plus 1\% bovine serum albumin (BSA) for 30 min to block nonspecific binding. The samples were then incubated with a 1:100 dilution of the primary anti-villin antibody in PBS plus $1 \%$ BSA for $1 \mathrm{~h}$ at room temperature. The horse serum blocking solution was substituted for the primary antibody on negative controls. The slides were rinsed three times in PBS for 5 min each and incubated with a 1:1000 dilution of goat anti-mouse 
biotinylated secondary antibody in PBS plus 1\% BSA for $30 \mathrm{~min}$. After three additional washes in PBS, the bound antibody was detected by using the $\mathrm{ABC}$ complex method (Vectastain ABC system; Vector Labs, Inc., Burlingame, $\mathrm{CA}$ ) as recommended by the manufacturer. A $0.1 \%$ solution of 3,3'-diaminobenzidine in PBS served as a chromogen. The slides were lightly counterstained with hematoxylin, and the presence of villin-positive cell staining was assessed by two independent reviewers who were blinded to the identity of each sample.

\section{Western Blot Hybridization}

Protein was extracted from intestinal-type Barrett's metaplasia by detergent lysis in a buffer containing $1 \%$ Triton X-100, $10 \mathrm{mM}$ Tris-HCl, $150 \mathrm{mM} \mathrm{NaCl}, 5$ mM EDTA, and 10\% glycerol. Twenty micrograms of tissue protein was mixed with an equal volume of sample buffer $(125 \mathrm{mM}$ Tris- $\mathrm{HCl}, 150 \mathrm{mM} \mathrm{NaCl}, 5$ mM EDTA, $640 \mathrm{mM} \beta$-mercaptoethanol, 20\% glycerol, $4 \%$ sodium dodecyl sulfate (SDS), and $0.2 \%$ bromophenol blue). The samples were heat-denatured and separated by electrophoresis in 7.5\% SDS-polyacrylamide gels alongside pre-stained low-molecular-weight markers (Bio-Rad Laboratories, Richmond, CA). The proteins were transferred to nylon membranes and then incubated for $60 \mathrm{~min}$ in a blocking solution containing $0.1 \%$ Tween $20,100 \mathrm{mM}$ Tris base, $0.9 \% \mathrm{NaCl}$, and $3 \%$ powdered milk. The membranes were then incubated with a 1:200 dilution of the anti-villin monoclonal antibody (Chemicon Intl., Inc.) and then with a 1:2000 dilution of biotinylated goat anti-mouse immunoglobulin G. The avidin-biotin complex method and a mouse immunodetection kit (Vectastain ABC system) were used to detect the villin protein. A $0.1 \% 3,3^{\prime}$-diaminobenzidine solution was used as a chromogen, allowing visualization of the villin protein band.

\section{Northern Blot Hybridization}

Total cellular RNA was extracted from frozen normal esophagus, intestinal-type Barrett's metaplasia, and normal gastric tissue by using Trizol reagent as recommended by the manufacturer (Life Technologies, Gaithersburg, MD). Ten micrograms of each RNA sample was size fractionated by electrophoresis in $1.2 \%$ agarose gels containing $2.2 \mathrm{M}$ formaldehyde. The samples were then vacuum-transferred to nylon membranes (Gene Screen Plus; NEN, Wilmington, $\mathrm{DE})$, and the membranes were prehybridized in $5 \times$ standard saline phosphate with EDTA $(0.9 \mathrm{M} \mathrm{NaCl}$, $50 \mathrm{mM} \mathrm{NaPO}_{4}$ pH 7.7, 5 mM EDTA), 5× Denhardt's, $3 \%$ dextran sulfate, $3 \%$ SDS, $50 \%$ formamide, 100 $\mu \mathrm{g} / \mathrm{ml}$ heat-denatured salmon-sperm DNA, and 25 $\mu \mathrm{g} / \mathrm{ml}$ yeast tRNA for $1-2 \mathrm{~h}$ at $48^{\circ} \mathrm{C}$. The villin cDNA was obtained by using primers derived from published cDNA villin sequences; the $5^{\prime}$ primer was $5^{\prime}$ CCACAGAGATGCCTGACTTC-3', and the $3^{\prime}$ primer was 5'-GAGGTTTTGTTCCTTCCATCG-3' $[14,19]$.
These villin-specific primers are located in the coding region for the villin protein head piece. The expected polymerase chain reaction product of $563 \mathrm{bp}$ was obtained and gel-purified, and the sequence was confirmed by automated DNA sequencing at the Sequencing Core Facility at the University of Michigan. The villin cDNA probe was labeled with $\left.{ }^{32} \mathrm{P}\right] \mathrm{dCTP}$ (Amersham Corp., Arlington Heights, IL) by the random primer-labeling method (Life Technologies). Unincorporated $\left[{ }^{32} \mathrm{P}\right] \mathrm{dCTP}$ was removed by Sephadex G-50 exclusion chromatography, and 1.5 $\times 10^{6} \mathrm{cpm} / \mathrm{ml} \mathrm{cDNA}$ probe was hybridized with the membrane in a $48^{\circ} \mathrm{C}$ shaking water bath for $16 \mathrm{~h}$. The membranes were washed twice in $2 \times$ standard saline citrate and $1 \% \mathrm{SDS}$ at $60^{\circ} \mathrm{C}$ for $20 \mathrm{~min}$ each time and then twice in $0.1 \times$ standard saline citrate at room temperature for $30 \mathrm{~min}$ each time. Autoradiograms were prepared by using $\mathrm{x}$-ray film (Hyperfilm-MP; Amersham Corp.) and intensifying screens. Hybridization band intensities were quantified by scanning laser densitometry (Molecular Dynamics, Inc., Sunnyvale, CA), and loading and transfer were assessed by rehybridization of the blots with an oligo probe specific for the $28 \mathrm{~S}$ ribosomal RNA as previously described [20].

\section{RESULTS}

Villin Expression and Staining Patterns in Esophageal Brushings

Previous analyses performed in our laboratory demonstrated the abundant expression of the villin protein in $100 \%$ of Barrett's intestinal metaplasia [10]. The characteristic villin staining pattern observed in intestinal-type Barrett's metaplasia was intense brushborder staining of the columnar epithelium apical surface (Figure 1A). This distinct pattern of villin expression illustrates the staining pattern we expected to find among the individual columnar epithelial cells from brushings of patients with intestinal-type Barrett's metaplasia. In contrast, no villin expression was detected in cryostat sections of either normal esophageal squamous epithelium or gastric tissue (Figure $1 \mathrm{~A}$ and $\mathrm{B}$ ).

Villin was observed in the esophageal brushings of $81 \%$ (17 of 21 ) of patients who were confirmed to have the diagnosis of Barrett's metaplasia at the time of endoscopy or had previously been documented as having this metaplastic mucosa. The characteristic brush-border villin staining present in the intestinal-type Barrett's columnar epithelium was also observed among individual columnar cells from the brushings of all these patients (Figure 1C, D, and E). Neither the normal esophageal squamous cells nor any of the often abundant blood cells present, however, demonstrated villin staining (Figure 1C). Groups of Barrett's cells also stained positive for villin, and when aggregates of Barrett's mucosa cells were viewed from the apical surface end on, a honeycomb-like 

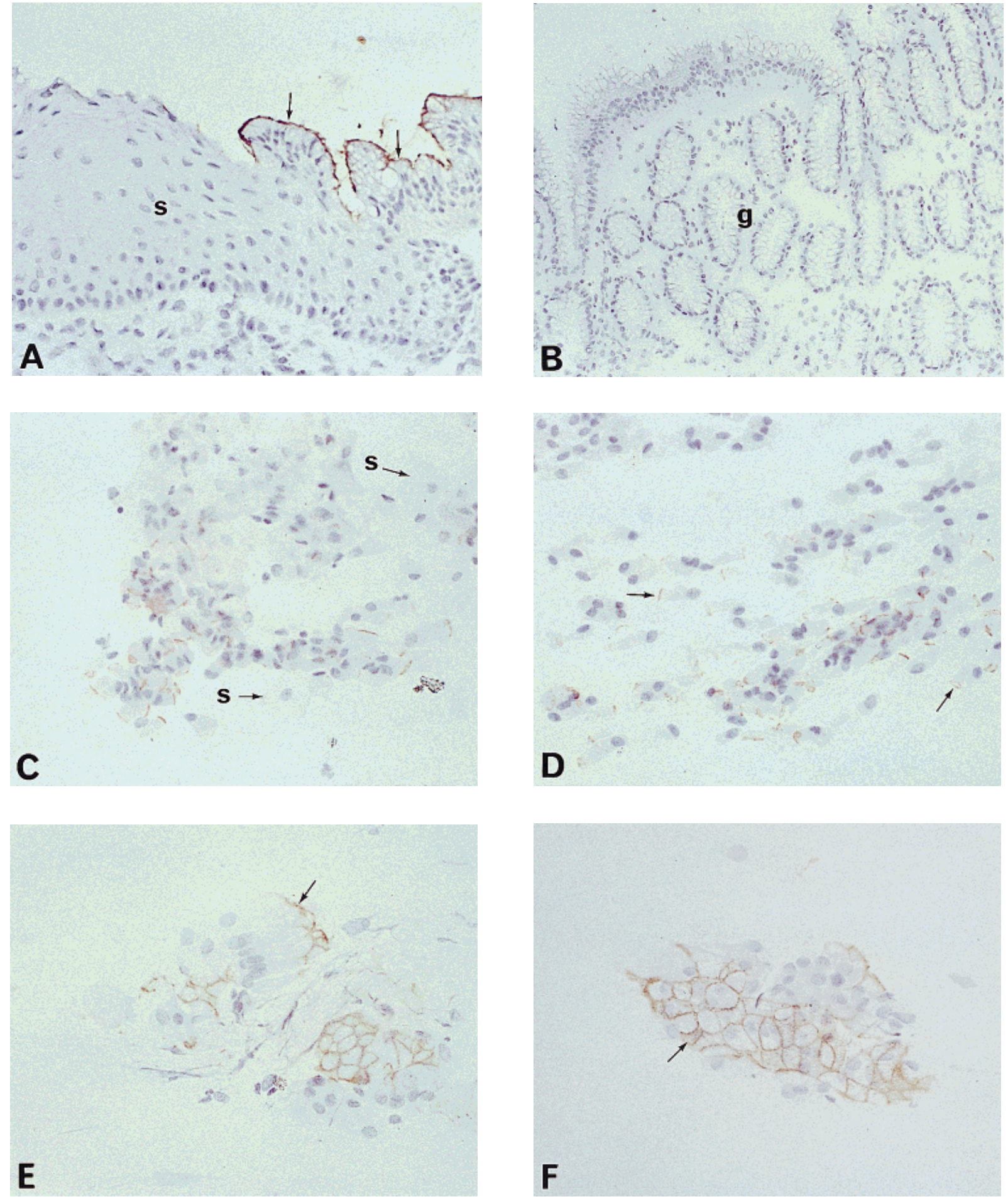

Figure 1. Villin expression in cryostat sections of normal esophageal squamous epithelium, Barrett's esophagus and normal gastric mucosa and in brushings of normal squamous epithelium and Barrett's metaplasia. (A) Normal squamous mucosa (s) demonstrates no expression of villin, whereas well-organized, brush-border staining (arrows) is observed in the intestinal-type Barrett's metaplasia. (B) No staining for villin was detected in normal gastric tissue $(\mathrm{g})$ in either the surface or glandular cells. (C) Esophageal brushings demonstrating that fried egg-shaped normal squamous mucosal cells (s, arrows) show no expression of villin and are easily discernible from the villin-positive co-

lumnar cells. (D) Esophageal brushings of Barrett's metaplasia containing columnar cells showing basally located nuclei and strong apical brush-border staining (arrows) similar to that observed in cryostat sections of Barrett's metaplasia. ( $E$ and F) The honeycomb-like villin staining pattern (arrow) formed by aggregates of columnar epithelial cells in brushings of Barrett's metaplasia. The cells shown in panel $\mathrm{F}$ are oriented to show the apical ends, and a mesh-like distribution of villin is apparent in some cells (arrow). All sections and brushings were lightly counterstained with hematoxylin. Magnifications: panels $A$ and $B, 100 x$; panels $C-F$, 200x. 
Table 1. Summary of Villin Protein Expression in Esophageal Brushings

\begin{tabular}{lcc}
\hline Brushings & No. of cases examined & No. villin positive \\
\hline Confirmed Barrett's esophagus & 21 & $17(81 \%)^{*}$ \\
No Barrett's esophagus & 4 & $0(0 \%)$ \\
Non-confirmed Barrett's esophagus ${ }^{\dagger}$ & 2 & $0(0 \%)$ \\
Normal esophagus & 4 & $0(0 \%)$ \\
Normal gastric & 4 & $0(0 \%)$ \\
\hline
\end{tabular}

*The brushings of one patient diagnosed with intestinal-type Barrett's metaplasia contained no discernable columnar epithelial cells, and the patient was grouped among the negative villin cases.

${ }^{\dagger}$ Brushings from patients whose pathology reports indicated the inability to confirm the columnar cells as representing Barrett's metaplastic cells.

appearance of villin-stained columnar epithelial cells was observed (Figure 1F). As shown, on the apicalmost end of the cells, either a light meshwork of villin or the absence of staining except for a ring-like structure was often observed.

The brushings from only 154\% (three of 21) of patients with a prior diagnosis of Barrett's metaplasia exhibited columnar epithelial cells that were negative for villin expression or exhibited low levels of atypical diffuse staining near the apical membrane. One patient's brushings lacked any discernible columnar epithelial cells (5\%). Brushings from all four patients who had not been diagnosed with Barrett's intestinal metaplasia were negative for villin staining. The staining results from the brushings of two patients whose medical records were inconclusive as to the diagnosis of Barrett's metaplasia demonstrated the diffuse atypical staining mentioned above and were deemed negative for villin. Brushings of four normal esophagus and four normal gastric tissue samples were negative for villin expression as well.

To confirm the specificity of the monoclonal antibody used for detecting villin in the brushings, western blot analysis of samples of intestinal-type Barrett's metaplasia was examined by using the anti-villin

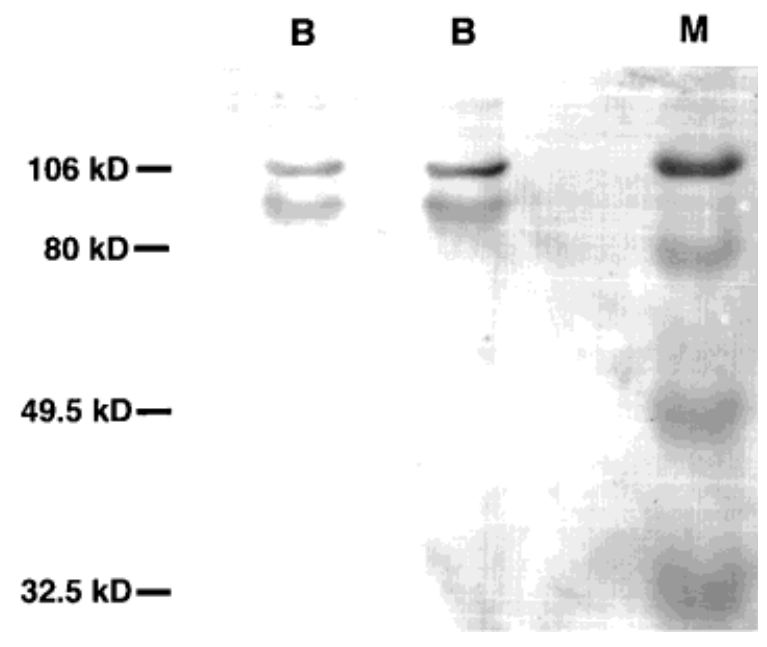

Figure 2. Western blot analysis of villin protein expression in Barrett's metaplasia. A band corresponding to the $95-\mathrm{kDa}$ villin protein was detected in the samples of Barrett's metaplasia (B). M, pre-stained molecular weight marker. antibody. As shown in Figure 2, an intensely staining band of $95 \mathrm{kDa}$, which is consistent with the known size of the villin protein, and a lighter-staining smaller band were observed.

\section{Villin Gene Expression}

Columnar cells exhibiting either atypical or negative staining for villin might represent gastric or gastric-like columnar epithelial cells present in the esophageal brushings. To determine whether expression of the villin gene is confined to Barrett's metaplasia, northern blot analysis of the normal esophagus, intestinal-type Barrett's metaplasia, and gastric tissue from five patients was performed. Normal human ileum served as a positive control for villin mRNA expression. Villin mRNA was abundant in all samples of Barrett's intestinal metaplasia and demonstrated the two 3.5- and 2.7-kb mRNAs that were identical in size and of similar proportion to those present in the normal ileum (Figure 3). In contrast, villin mRNA was not detected in either the normal esophagus or gastric tissue of any patient. This demonstrates that the villin gene is not expressed in the normal esophagus or normal gastric mucosa to any appreciable extent, and thus it is unlikely these tissues would contribute villin-positive stained cells to the esophageal brushings.

\section{DISCUSSION}

The results of these analyses are consistent with those of the two previous examinations of the ex-

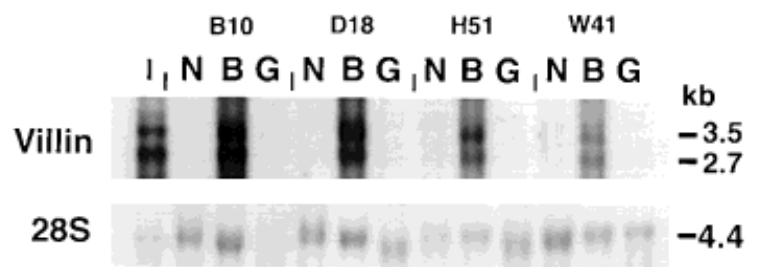

Figure 3. Northern blot analysis of villin mRNA in normal esophageal squamous mucosa (N), Barrett's metaplasia (B), and normal gastric mucosa (G). Results from four of the five patients are shown. Villin mRNAs of 3.5 and $2.7 \mathrm{~kb}$ identical to those of the normal ileum (I) are present in all samples of Barrett's metaplasia but not in either the normal esophageal or gastric mucosa. The signal from the $28 \mathrm{~S}$ rRNA is shown in the bottom panel. 
pression and localization of the villin protein in intestinal-type Barrett's metaplasia $[10,11]$. Villin's high-level, characteristic brush-border expression makes it a promising candidate for an intestine-specific marker that may be used to detect intestinaltype Barrett's metaplasia in patients at high risk for developing this metaplasia. We observed that in the esophageal brushings of $81 \%$ of patients with prediagnosed intestinal-type Barrett's metaplasia, there were individual columnar epithelial cells that expressed villin. The strong apical staining observed in the brushed cells closely resembles the characteristic villin staining pattern detected in cryostat sections of intestinal-type Barrett's epithelium and small intestinal mucosa $[10,11]$. Blood cells, normal esophageal squamous cells, and gastric-type columnar epithelial cells displayed no villin staining, so the villin-positive Barrett's columnar epithelial cells were easily distinguished when these other cells were present in the brushings.

The absence of villin immunoreactivity in the gastric mucosa and gastric brushings may suggest an explanation for the negative staining results observed in the brushings of $14 \%$ (three of 21 ) of the patients with preexisting Barrett's metaplasia. It is possible that cells from the gastric cardias or esophagogastric junctions of these three patients were brushed instead of cells from the areas of intestinal-type Barrett's metaplasia, producing brushings that consisted mostly of gastric-type columnar epithelial cells. Northern blot analysis demonstrated that gastric mucosa does not express the villin gene. This is consistent with our immunohistochemical results, which showed that villin protein was not detectable in gastric columnar cells. Although brushings from these three patients did not demonstrate the characteristic strong brush-border staining, it is also possible that either low-level or altered villin protein was present in the columnar epithelial cells. Altered villin localization may have given rise to the low-level, atypical diffuse staining observed, which was scored as negative for villin expression in this study. Several factors may alter the cellular localization of the villin protein in the brushings, including repeated freezing and thawing of the brushing slides or exposure to excessive moisture before staining.

It is therefore necessary to establish objective criteria with which to evaluate the staining and expression patterns of villin protein in the individual columnar epithelial cells obtained from esophageal brushings of patients at risk for developing Barrett's metaplasia. In this study, the independent reviewers classified the esophageal brushings as positive only when multiple areas of cells demonstrating highly expressed and distinct brush-border villin staining of columnar cells were present. Villin-positive cells viewed from the side exhibited a basally located nucleus and a strong band of staining at the apical surface. Aggregates of columnar cells oriented with their apical sides facing the viewer stained as distinct rings that resembled either honeycombs or net-like structures. As described above, any low-level immunoreactivity that appeared diffuse, grainy, cytoplasmic, or otherwise nonspecific was scored as negative for villin expression. Filamentous staining in large aggregates of cells was attributed to trapped primary antibody and was also considered a negative result.

The use of esophageal brush cytology in conjunction with villin immunohistochemical analysis may provide a simple yet effective means for identifying patients with intestinal-type Barrett's metaplasia among those patients who are at an increased risk for developing this condition due to chronic reflux symptoms. This procedure could be useful as a preliminary screening method for patients, with confirmatory endoscopy and biopsy following if villin-positive columnar cells consistent with Barrett's metaplasia are detected. Unlike endoscopy, the brushing procedure can be performed without sedation during a routine visit to the physician's office, perhaps by using a nasogastric tube or by balloon cytology [21]. Although this procedure will undoubtedly not replace the need for confirmatory endoscopy and biopsy, its greatest use may be to help identify the presence of intestinal metaplasia in these high-risk individuals. Because villin is strongly and characteristically expressed in individual columnar epithelial cells of intestinal-type Barrett's metaplasia, these results suggest that this technique may be most useful for identifying intestinal-type metaplasia in patients with chronic gastroesophageal reflux symptoms who may be at risk for developing this premalignant mucosa. Future studies will examine the efficacy of this technique relative to the known extent of Barrett's mucosa present in these patients, because it is very likely that extensive Barrett's mucosa would be more easily detected. However, given the sensitivity of this procedure, even individual villin-positive columnar cells should be detectable in patients with small segments of Barrett's mucosa.

\section{ACKNOWLEDGMENTS}

This work was supported by the American Cancer Society grant CN-171 and the Roy Weber Research Endowment.

\section{REFERENCES}

1. Blot WJ, Devesa SS, Kneller RW, Fraumeni JF. Rising incidence of adenocarcinoma of the esophagus and gastric cardia. JAMA 1991;265:1287-1289.

2. Spechler SJ, Goyal RK. Barrett's esophagus. N Engl J Med 1986;315:362-371.

3. Li H, Walsh T, Hennessy TP. Carcinoma arising in Barrett's esophagus. Surgical Gynecology and Obstetrics 1992;175:167-172.

4. Isenberg JL, McQuaid KR, Laine L, Rubin W. Acid-peptic disorders. In: Yamada T, Alpers DH, Owyang C, Powell D, Silverstein FE, editors. Textbook of gastroenterology, 1st ed. Philadelphia: Lippincott; 1991. p 1241-1313.

5. Appleman HD. Barrett's esophagus: Morphological considerations. In: Orringer MB, Zuidema GD, editors. Surgery of 
the alimentary tract, 3rd ed. Philadelphia: Saunders; 1991; 314-334.

6. Winters D, Spurling TJ, Chobanian SJ, et al. Barrett's esophagus: A prevalent, occult complication of gastroesophageal reflux disease. Gastroenterology 1987;92:118-124.

7. Nishizawa M, Okada T, Hosoi T, Makino T. Detecting early esophageal cancers, with special reference to the intraepithelial stage. Endoscopy 1984;16:92-94.

8. Wu GD, Beer DG, Moore JH, Orringer MB, Appleman HD, Traber PG. Sucrase-isomaltase gene expression in Barrett's esophagus and adenocarcinoma. Gastroenterology 1993;105:837-844.

9. Moore JH, Lesser EJ, Erdody DH, Natale RB, Orringer MB, Beer DG. Intestinal differentiation and p53 gene alterations in Barrett's esophagus and esophageal adenocarcinoma. Int J Cancer 1994;56:487-493.

10. Regalado SP, Nambu Y, lannettoni MD, Orringer MB, Beer DG Villin protein expression in Barrett's esophagus and esophageal adenocarcinomas. Mol Carcinog 1998;22:182-189.

11. Kumble S, Omary MB, Fajardo LF, Triadafilopoulos G. Multifocal heterogeneity in villin and Ep-CAM expression in Barrett's esophagus. Int J Cancer 1996;66:48-54.

12. Bretscher A, Weber K. Villin: The major microfilament-associated protein of the intestinal microvillus. Proc Natl Acad Sci USA 1979:76:2321-2325.

13. Shibayama T, Carboni JM, Mooseker MS. Assembly of the intestinal brush border: Appearance and redistribution of microvillar core proteins in developing chick enterocytes. J Cell Biol 1987; 105:335-344.
14. Pringault $E$, Robine $S$, Louvard $D$. Structure of the human villin gene. Proc Natl Acad Sci USA 1991;88:10811-10815.

15. Grone HJ, Weber K, Helmchen U, Osborn M. Villin-A marker of brush border differentiation and cellular origin in human renal cell carcinoma. Am J Pathol 1986;124:294-302.

16. Bacchi CE, Gown AM. Distribution and pattern of expression of villin, a gastrointestinal-associated cytoskeletal protein, in human carcinomas: A study employing paraffin-embedded tissue. Lab Invest 1991:64:418-424.

17. Dudouet $B$, Jacob $L$, Beuzeboc $P$, et al. Presence of villin, a tissue-specific cytoskeletal protein, in sera of patients and an initial clinical evaluation of its value for the diagnosis and follow-up of colorectal cancers. Cancer Res 1990;50:438-443.

18. Cameron AJ, Zinsmeister AR, Ballard DJ, Carney JA. Prevalence of columnar-lined (Barrett's) esophagus: Comparison of population-based clinical and autopsy findings. Gastroenterology 1990;99:918-922.

19. Arpin $M$, Pringault $E$, Finidori J, et al. Sequence of human villin: A large duplicated domain homologous with actin-severing proteins and a unique small carboxyl-terminal domain related to villin specificity. J Cell Biol 1988;107:1759-1766.

20. Hanson LA, Nuzum EO, Jones BC, Malkinson AM, Beer DG. Expression of the glucocorticoid receptor and Ki-ras genes in urethan-induced mouse lung tumors and transformed cell lines. Exp Lung Res 1991;17:371-387.

21. Falk GW, Chittajallu R, Goldblum JR. Surveillance of patients with Barrett's esophagus for dysplasia and cancer with balloon cytology. Gastroenterology 1997;112:1787-1797. 